\title{
Model Pemantau Kelembaban dan Irigasi Sawah Otomatis Berbasiskan Internet of Things
}

\author{
April Firman Daru1, Whisnumurti Adhiwibowo ${ }^{2,}$ Alauddin Maulana Hirzan $^{3 *}$ \\ 1,23)Program Studi Teknik Informatika, Fakultas Teknologi Informasi dan Komunikasi, Universitas Semarang \\ Jl. Soekarno-Hatta Tlogosari, Semarang 50196 \\ *email:maulanahirzan@usm.ac.id
}

(Naskah masuk: 03 Februari 2021; diterima untuk diterbitkan: 4 Juni 2021)

\begin{abstract}
ABSTRAK - Perkembangan teknologi masa kini memiliki dampak yang sangat penting dalam kemajuan kehidupan manusia. Selain membantu banyak sektor kehidupan manusia, teknologi juga dapat membantu bidang pertanian, Pertanian memiliki persyaratan yang ketat agar tanaman bisa tumbuh sempurna. Tingkat kelembaban yang sangat mempengaruhi hasil panen, sehingga kelembaban sawah harus dijaga kestabilannya. Kelembaban yang tidak sesuai menghambat pertumbuhan tanaman. Tantangan utama dari pengairan sawah adalah proses pengairan yang dilakukan secara manual, sehingga memerlukan tenaga serta waktu yang banya. Oleh karena itu, penelitian ini memiliki tujuan untuk mendesain sebuah model pemantau kelembaban dan pengairan otomatis berbasiskan Internet of Things (IoT) untuk meringankan beban petani untuk mengairi sawahnya. Model ini dilengkapi dengan sensor kelembaban untuk memonitor kelembaban serta pompa air mini untuk mengalirkan air sebagai pengontrol kelembaban tanah. Selain itu model ini juga dilengkapi dengan konektivitas WiFi sehingga memudahkan para petani untuk memantau keadaan sawah mereka secara realtime. Dari proses evaluasi model yang dilakukan model yang diusulkan mampu mempertahankan kelembaban hingga 66. 8\% secara efektif dalam kurun waktu 24 jam. Selain itu, data kelembaban yang dipantau memiliki korelasi yang tinggi $(r=1)$. Sehingga dapat disimpulkan bahwa model yang diusulkan ini dapat memantau dengan baik serta meringankan pekerjaan petani dan membantu meningkatkan produktivitas kerjanya secara efisien.
\end{abstract}

Kata Kunci - Internet of Things; Irigasi; Sawah; Kelembaban; Otomatisasi

\section{Automated Moisture Control and Paddy Irrigation Model based on the Internet of Things}

\begin{abstract}
Today's technological developments have a significant impact on the progress of human life. Apart from helping many sectors of human life, technology can also help agriculture. Unlike other fields, rice fields have strict requirements to ensure plants can grow well. Since the humidity level influences the harvest result, the consistency of the humidity must be well-maintained. The insufficient moisture may inhibit plant growth in the rice field. The main challenge of irrigating rice fields is the manual process carried out by the farmer. This process requires more energy and time to cover larger areas. Therefore, this study aims to design a humidity monitoring and automatic irrigation model based on the Internet of Things to reduce the workload. This model is equipped with sensors to monitor moisture and a water pump to control the soil moisture. Besides that, this model is equipped with WiFi connectivity for monitoring the humidity level of their rice fields. From the model evaluation process, this model can stabilize soil moisture for $66.8 \%$ within 24 hours effectively. Besides that, the correlation between monitored data was high ( $r=1)$. Hence, it can be concluded that the proposed model can decrease the farmers' work and increase their productivity efficiently.
\end{abstract}

Keywords - Internet of Things; Irrigation; Rice Field; Humidity; Automation 


\section{Pendahuluan}

Faktor kelembaban tanah di persawahan merupakan salah satu faktor yang sangat penting di dalam memaksimalkan hasil panen. Tanaman padi yang ada dipersawahan membutuhkan kelembaban tanah yang cukup untuk memaksimalkan pertumbuhannya[1]. Kelembaban tanah yang stabil memberikan hasil panen yang berkualitas. Sebaliknya, apabila kelembaban tanah di sawah kurang dapat menghambat pertumbuhan tanaman untuk tumbuh secara optimal[2]. Kurangnya kandugan air dalam tanah menghambat proses fotosintesis yang diperlukan oleh tanaman untuk memproduksi nutrisi tumbuh kembangnya. Nilai pertumbuhan dari tanaman di sawah menurun sesuai dengan jumlah air yang tersedia. Selain dari sisi pertumbuhan, nilai protein larut air yang terkandung di dalamnya ikut terpengaruh[3]. Gambar 1 menunjukkan ilustrasi kandungan air dalam tanah.

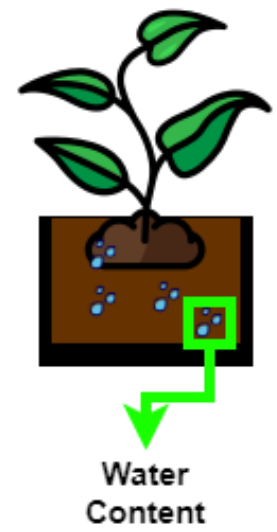

Gambar 1. Kandungan Air Dalam Tanah

Ketatnya persyaratan tanaman yang tumbuh di sawah inilah yang menjadi masalah utama yang sering dialami petani. Selama ini, para petani masih menggunakan cara manual untuk menjaga kelembaban sawahnya dengan cara mengaktifkan pompa air yang tersedia. Proses pengairan yang dilakukan oleh para petani inilah yang menjadi tantangan utama pemeliharaan sawah agar bisa dilakukan secara otomatis untuk mengurangi beban para petani dalam bercocok tanam. Dengan meningkatnya produktivitas para petani, dapat meningkatkan pula produksi pangan dalam negeri sehingga dapat mengurangi frekuensi impor beras yang masih dilakukan untuk memenuhi kebutuhan pangan.

Banyak penelitian-penelitian yang mengkaji pemantauan kelembaban tanah hingga otomatisasi pengairan tanaman baik untuk perkebunan hingga persawahan. Salah satu penelitian yang berfokuskan kepada pemantauan kelembaban untuk tanaman aerophonic, menghasilkan sebuah aplikasi pemantauan kelembaban yang dapat dipantau dengan mudah dari perangkat gawai Android[4]. Penelitian tersebut kembali dikembangkan dengan menambahkan sensor DHT11 untuk mendeteksi kelembaban. Berdasarkan hasil penelitian yang dibuat, model ini mampu mendeteksi kelembaban lebih stabil dan tahan lama dari korosi dari penelitian lainnya[5].

Dari perangkat pemantau kelembaban kemudian dikembangkan lebih lanjut dalam bentuk pengendalian pengairan otomatis. Penelitian yang berfokuskan kepada pengairan otomatis menghasilkan sebuah model pemantau serta pengendalian kelembaban tanah melalui jalur GSM dengan perangkat Arduino[6]. Model ini kembali dikembangkan dengan menggunakan dua jenis perangkat yang berbeda untuk pemantauan dan pengendalian. Penelitian yang dilakukan ini menghasilkan sebuah model yang dapat merekam dan mengendalikan pengairan melalui media cloud[7]. Pendekatan Internet of Things untuk improvisasi kembali dilakukan dengan menambahkan teknologi layanan cloud untuk memroses data yang direkam. Model eksperimen yang dihasilkan oleh penelitian ini mampu merekam, memproses data melalui cloud, sehingga dapat memberika rekomendasi tindakan yang harus dilakukan[8].

Dari model-model yang dihasilkan dari penelitian, ditemukan beberapa kelemahan kelemahan seperti tidak adanya model pengendalian pengairan tanaman secara otomatis, penggunaan GSM sebagai pemantau data yang tidak efektif dan berbiaya besar untuk mengirimkan data, dan penggunaan cloud yang tidak efektif digunakan untuk area-area pedesaan yang tidak terjangkau jaringan internet yang cepat.

Oleh karena itu, penelitian ini memiliki tujuan untuk membuat sebuah model pemantau kelembaban dan pengairan otomatis yang dikendalikan oleh perangkat Internet of Things. Model ini dilengkapi dengan sensor kelembaban untuk memantau keadaan sawah, serta pompa pengairan untuk mengalirkan air ketika kelembaban menurun. Komunikasi antara model pengendali menggunakan Blynk sehingga data yang dikirimkan bisa melalui jaringan internet secara real-time[9].

Model ini memerlukan sebuah board yang mampu menerima data baik dalam bentuk analog maupun digital. Sebagai papan utama pemantau dan pengendali dari model tersebut digunakan mikrokontroler NodeMCU ESP8266 yang dilengkapi dengan sensor kelembaban tanah. Jika dibandingkan dengan Arduino Uno, NodeMCU lebih mudah untuk dikonfigurasikan, sumber daya terpusat dan kekuatan pemrosesan[10][11][12].

Dari model yang diusulkan ini diharapkan dapat 
meningkatkan produktivitas petani dengan mengurangi pengairan sawah yang dilakukan secara manual.

\section{METODE DAN BAHAN}

Penelitian ini menggunakan teknik eksperimen untuk mengumpulkan data-data yang diperlukan untuk analisis maupun evaluasi model pemantau dan pengendalian kelembaban sawah secara otomatis.

Untuk mengembangkan irigasi yang cocok untuk mengairi sawah, diperlukanlah data yang tepat mengenai pengairan persawahan yang dilakukan secara terus-menerus. Data ini kemudian dijadikan sebagai panduan untuk mendesain perangkat pemantauan yang diusulkan. Tabel 1 menunjukkan kebutuhan air untuk sawah.

Tabel 1. Kebutuhan Air di Persawahan

\begin{tabular}{ccc}
\hline No & $\begin{array}{c}\text { Tahap } \\
\text { Pertumbuhan }\end{array}$ & $\begin{array}{c}\text { Kebutuhan Air } \\
(\mathbf{m m})\end{array}$ \\
\hline 1 & Pembibitan & 40 \\
2 & Persiapan Lahan & 200 \\
3 & Penanaman & 458 \\
4 & Pengembangan & 417 \\
5 & Pematangan & 125 \\
\hline
\end{tabular}

Berdasarkan data di atas, proses penanaman sawah memerlukan kelembaban yang berbeda. Kebutuhan air tertinggi ada di tahap penanaman, sedangkan proses pembibitan memerlukan air yang sedikit[13]. sehingga dalam pengembangan modelnya dapat mencukupi kebutuhan air. Untuk dapat membaca kelembaban dengan baik, model dibangun dengan spesifikasi komponen seperti yang ditunjukkan pada Tabel 2.

Tabel 2. Spesifikasi Model Usulan

\begin{tabular}{|c|c|c|}
\hline No & Nama & Spesifikasi \\
\hline \multirow[t]{2}{*}{1} & NodeMCU & 32-bit RISC CPU, 64KiB \\
\hline & ESP8266 & $\begin{array}{l}\text { SRAM, 40MB Flash } \\
\text { Memory, dan } 802.11 \\
\text { b/g/n Wi-Fi }\end{array}$ \\
\hline \multirow[t]{2}{*}{2} & Soil Moisture & DC Input $3.3-5 \mathrm{~V}$, Skala \\
\hline & $\begin{array}{l}\text { Sensor FC-28 } \\
\text { Hygrometer }\end{array}$ & Deteksi 0-1023 \\
\hline 3 & Water Pump & - \\
\hline 4 & $L C D-16 X 2$ & $\begin{array}{l}5 \times 8 \text { pixel box, DC Input } \\
4,7-5,3 \mathrm{~V}\end{array}$ \\
\hline 5 & LCM1602 IIC & LCD I2C Interface \\
\hline 6 & Songle Relay & Input DC 5V 10A \\
\hline 7 & Power Adapter & Input DC 5V 2A \\
\hline
\end{tabular}

Komponen-komponen ini kemudian dirakit sesuai dengan skematis yang telah ditentukan. Skema sirkuit dari model yang diusulkan ditunjukkan pada Gambar 2.

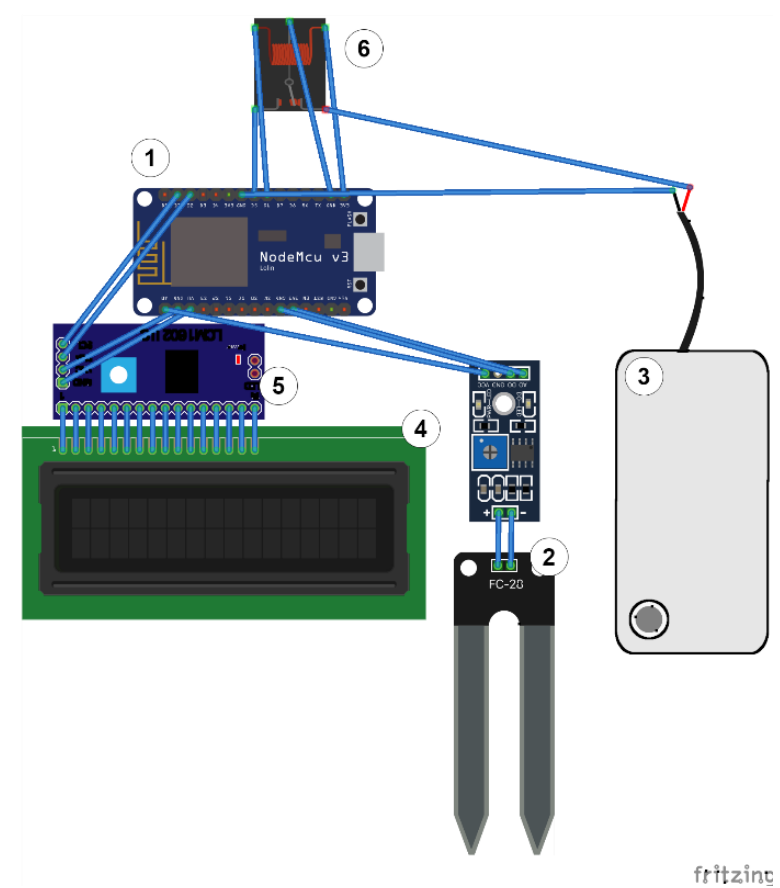

Gambar 2. Skematik Sirkuit Model

Skematis sirkuit model ini menunjukkan pemasangan kabel yang tepat sehingga tidak menimbulkan korsleting dan merusak komponenkomponen sensitif yang ada. Dalam eksperimen ini, model terdiri dari 1) NodeMCU sebagai pusat pemrosesan, 2) Soil Moisture Sensor untuk mendeteksi kelembaban, 3) Pompa berukuran kecil untuk memompa air, 4) LCD berukuran 16x2 untuk menampilkan data, 5) Antarmuka I2C untuk mendukung bagian LCD, 6) Relay 5V untuk mengaktifkan pompa. Power Adapter digunakan untuk menyalakan model, sehingga dibutuhkan daya yang tepat.

Dalam komunikasi dengan klien atau penerima data, model ini menggunakan jaringan nirkabel yang terkoneksi langsung melalui akses poin jaringan. Berikut adalah topologi jaringan nirkabel yang digunakan untuk komunikasi perangkat ke internet ditunjukkan pada Gambar 3.

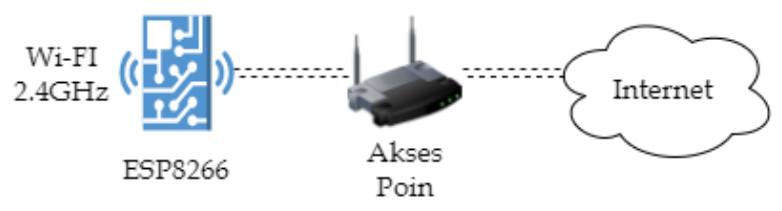

Gambar 3. Topologi Jaringan Nirkabel Model

Model dikonfigurasikan untuk menggunakan antarmuka nirkabel agar terkoneksi dengan jaringan nirkabel ke akses poin yang telah disediakan. Akses poin dikonfigurasikan dengan menggunakan frekuensi 2,4GHz (protokol 802.11g) demi kompatibilitas protokol Wi-Fi yang dimiliki oleh model. Akses poin yang terhubung dengan model 
juga dihubungkan dengan internet melalui kabel ethernet. Model yang sudah terkoneksi dengan internet dapat mengirimkan data ke peladen Blynk untuk menyimpan data secara aman[14]. Ilustrasi proses pengiriman dan pengambilan data dari/ke peladen Blynk ditunjukkan pada Gambar 4.

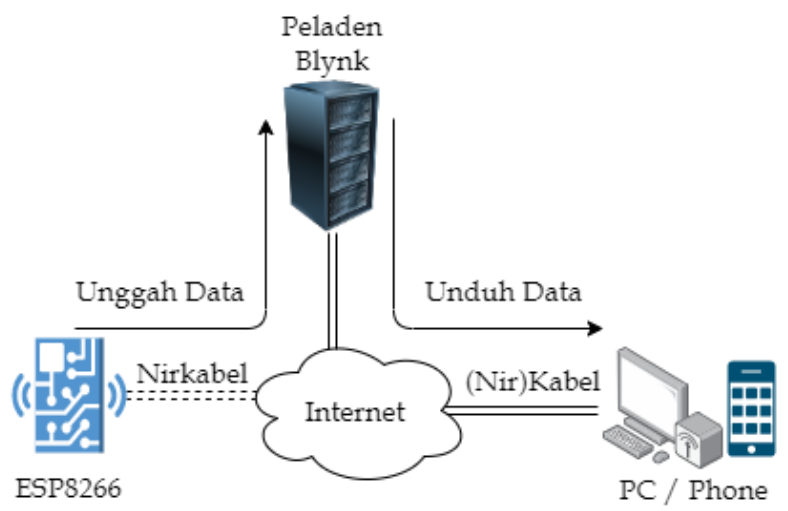

Gambar 4. Ilustrasi Komunikasi Model

Komunikasi dengan menggunakan Blynk memerlukan pustaka yang dipasang di dalam model. Pustaka ini digunakan untuk menginisialisasi komunikasi peladen, juga untuk mengirimkan data ke peladen. Proses pengunggahan data dilakukan melalui port 443 TCP (Transmission Control Protocol) memanfaatkan keamanan dari teknologi Secure Socket Layer(SSL)/Transport Layer Security. Data-data yang sudah diunggah ke peladen dapat diakses dengan menggunakan aplikasi Blynk gawai pintar atau web kapan saja.

Selain dalam hal komunikasi, agar model dapat bekerja dengan baik diperlukanlah sebuah algoritme yang tepat untuk membaca, memroses, mengambil tindakan sesuai data yang didapatkan. Algoritme ini dikembangkan dengan menggunakan pendekatan Software Development Life Cycle agar algoritme yang diusulkan akurat dan sesuai. Ilustrasi pendekatan pengembangan algoritme ditunjukkan pada Gambar 5 .

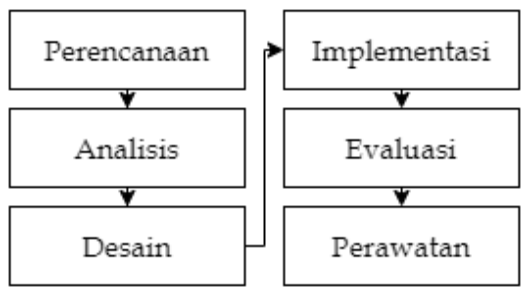

Gambar 5. Pendekatan Pengembangan Algoritme

Untuk mengembangkan algoritme, perencanaan dilakukan dengan menyiapkan aspek-aspek yang berkaitan dengan penelitian serta pengambilan contoh data sebagai indikator utama threshold.

Data kelembaban yang diambil dalam tahap Perencanaan kemudian dianalisa untuk mencari nilai yang tepat sebagai nilai batasan tanah kering, dan basah. Nilai Moisture sebesar 700MV dan 600MV yang didapatkan dari sensor ini digunakan sebagai dasar penentuan pengaktifan pompa.

Setelah itu algoritme untuk mempermudah implementasi ke model. Algoritme disusun dalam bentuk flowchart untuk mengidentifikasikan aksi yang dilakukan ketika membaca data yang diterima dari sensor. Selain itu, bagan ini juga mendeskripsikan proses inisialisasi komponen yang diperlukan oleh model seperti yang ditunjukkan pada Gambar 6.

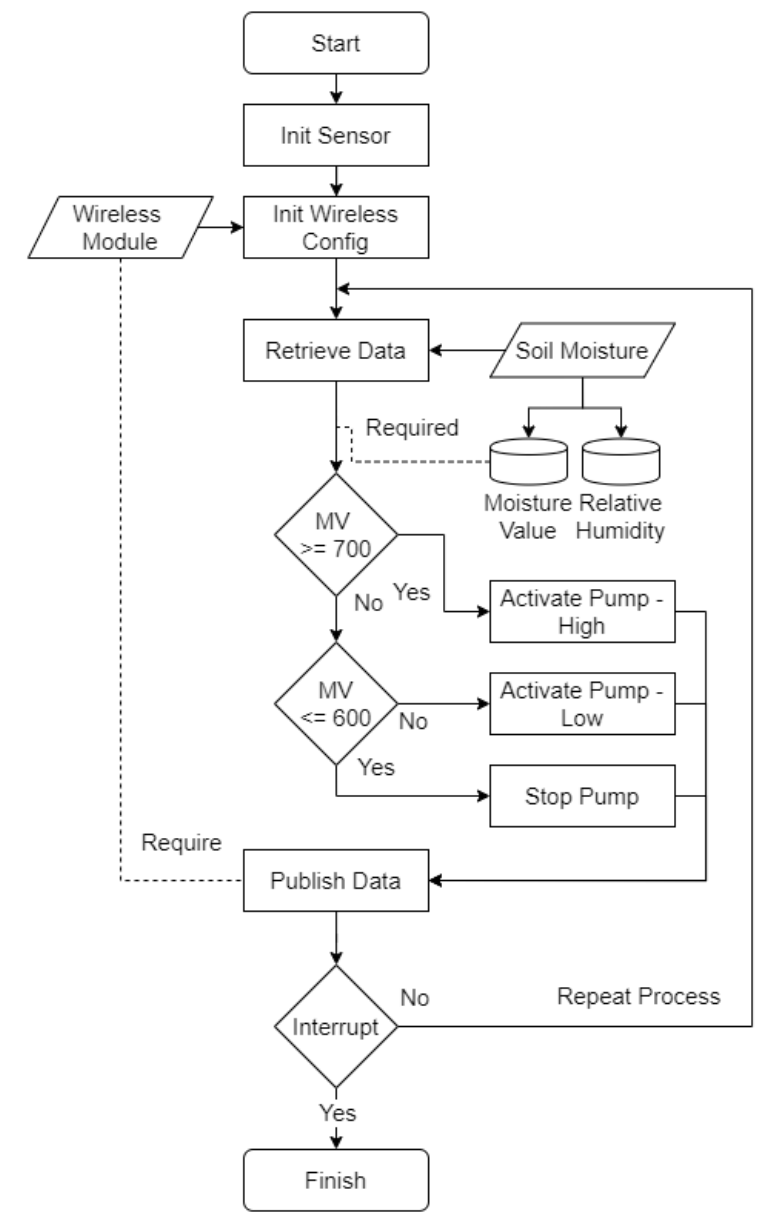

Gambar 6. Algoritme Model

Algoritme ini mengatur bagaimana model mengambil, memproses dan merespons kondisi kelembaban yang ada di dalam tanah dari sensor yang terpasang serta melakukan publikasi data ke peladen yang telah dikonfigurasikan.

Proses ini dimulai dengan model melakukan inisialisasi sensor dan perangkat jaringan agar bisa terhubung ke internet. Ketika proses inisialisasi selesai, model akan melakukan pengambilan data dari sensor kelembaban yang telah ditancapkan ke dalam tanah. Model ini mengambil data berupa Moisture Value dan Relative Humidity yang nantinya digunakan untuk indikator pengaktifan pompa. Nilai dari Moisture Value (MV) ini akan menjadi acuan penentuan pengaktifan pompa. Tabel 3 menunjukkan batasan yang digunakan untuk IFBased Rules. 
Tabel 3. Aturan Batasan Moisture Value

\begin{tabular}{cll}
\hline No & \multicolumn{1}{c}{$\begin{array}{c}\text { Batasan } \\
\text { Nilai }\end{array}$} & \multicolumn{1}{c}{ Tindakan } \\
\hline 1 & $x>=700$ & Pompa Kekuatan Penuh \\
2 & $600<=x<=700$ & Pompa Kekuatan Sedang \\
3 & $x<=600$ & Pompa Mati \\
\hline
\end{tabular}

Dengan menggunakan batasan nilai, model dapat menentukan kapan mengaktifkan pompa. Apabila sensor mendeteksi Moisture Value sebanyak 700 atau lebih maka pompa akan dinyalakan untuk membasahi media tanam. Jika nilai MV berada di antara 700 hingga 600, maka model akan menjaga kelembaban tersebut dengan pompa tenaga rendah. Namun jika nilai MV di bawah 600, maka model akan mematikan pompa agar menghemat sumber daya air dan listrik. Proses pengambilan, pemrosesan data dan tindakannya akan terus-menerus berulang hingga interupsi terjadi. Jika interupsi terjadi, maka proses akan dimulai dari awal kembali.

Pemilihan Moisture Value sebagai acuan dikarenakan nilai MV adalah refleksi dari kandungan air di dalam tanah dalam bentuk cairan. Sedangkan nilai Relative Humidity merefleksikan kandungan air dalam bentuk gas. Sehingga nilai MV memiliki keakuratan yang lebih baik dibandingkan nilai RH di dalam tanah[15], [16].

Algoritme ini kemudian diimplementasikan dengan cara menulis algoritme ke perangkat NodeMCU ESP8266 dengan menggunakan perangkat lunak Arduino IDE. IDE ini tidak hanya dapat digunakan sebagai editor pemrograman, namun juga untuk menuliskan program (flash) dan memantau kondisi NodeMCU melalui kabel serial.

Untuk melakukan evaluasi dari model yang diusulkan ini, tahap eksperimen dilakukan untuk mengambil data-data yang diperlukan untuk evaluasi model yang diusulkan. Skenario eksperimen yang dilakukan memiliki skenario yang telah dikontrol sehingga mendapatkan data yang dikehendaki. Model ini akan diuji di sebuah media tanam berukuran kecil sebagai bentuk simulasi sawah. Ilustrasi proses eksperimen evaluasi model yang diusulkan ditunjukkan pada Gambar 7.

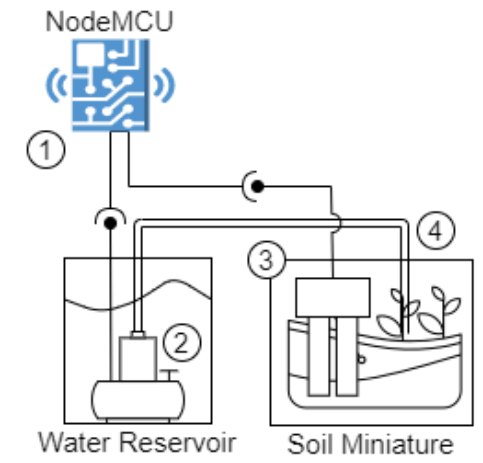

Gambar 7. Skenario Eksperimen Evaluasi
Proses eksperimen dijalankan dengan memasang sensor kelembaban (3) di dalam tanah hingga probe logam tertanam seluruhnya. Kemudian pompa air (2) dimasukkan ke dalam tanki berisikan air yang bersih. Pipa (4) yang terhubung dengan pompa air diarahkan ke miniatur tanah. NodeMCU (1) yang sudah terhubung dengan pompa dan sensor dinyalakan dengan catu dayanya.

Proses eksperimen ini dilakukan selama 24 jam penuh untuk mendapatkan data yang lebih detail. Pengambilan data Moisture Value melalui Analogue to Digital Converter (ADC) dan Relative Humidity dilakukan dalam selang waktu 1 menit.

Sebelum data dianalisis menggunakan analisa timeseries, data harus melalui pra-pemrosesan data. Hal ini dilakukan karena nilai dari Moisture Value masih berupa data 10-bit yang harus dikonversikan menjadi persentase[17]. Untuk mengubah nilai MV menjadi persettase MV harus dikalkulasikan menggunakan rumus sebagai berikut:

$$
\begin{aligned}
& \text { AnalogOutput }=\frac{A D C(\text { Moisture Value })}{1023} \\
& \text { Moisture }(\%)=100-(\text { AnalogOutput } * 100)
\end{aligned}
$$

Rumus-rumus ini digunakan untuk mengubah nilai analog yang ditangkap oleh sensor menjadi nilai persentase cairan di dalam tanah (Moisture \%). Hasil perhitungan dari persentase Moisture dan Relative Humidity menjadi acuan evaluasi di penelitian ini.

Proses evaluasi dari eksperimen dilakukan dengan cara menganalisa data timeseries yang telah disimpan di peladen Analisis yang pertama dilakukan adalah korelasi antara Moisture (\%) dengan Relative Humidity. Penelitian ini menggunakan korelasi Pearson untuk melihat hubungan kedua data tersebut. Berikut ini adalah rumus yang digunakan untuk menghitung nilai korelasi:

$$
r=\frac{\sum_{i}\left(x_{i}-\bar{x}\right)\left(y_{i}-\bar{y}\right)}{\sqrt{\sum\left(x_{i}-\bar{x}\right)^{2} \sum\left(y_{i}-\bar{y}\right)^{2}}}
$$

Korelasi ini tidak hanya dapat digunakan sebagai mencari relasi nilai, juga dapat mencari fitur dari data yang diberikan.

\section{HASIL DAN PEMBAHASAN}

Model yang diusulkan ini disusun di dalam sebuah kotak khusus untuk menghindari gangguan dari luar seperti tetesan maupun debu. Tampilan bagian dalam model ditunjukkan pada Gambar 8 . 


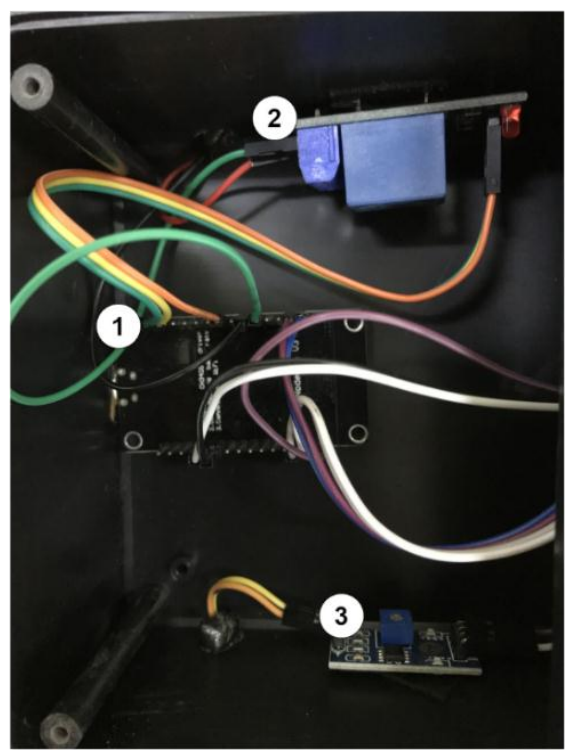

Gambar 8. Bagian Dalam Model

Bagian dalam ini berisi komponen-komponen yang memiliki kerentanan yang tinggi, sehingga perlu diamankan dari tetesan air maupun debu. Di sini terdapat komponen seperti 1) NodeMCU ESP8288 dengan bagian kaki terekspos keluar, 2) Relay yang terhubung dengan NodeMCU, dan 3) komponen bagian dari Soil Moisture Sensor yang juga terhubung dengan NodeMCU. Bagian luar dari model ditunjukkan pada Gambar 9.

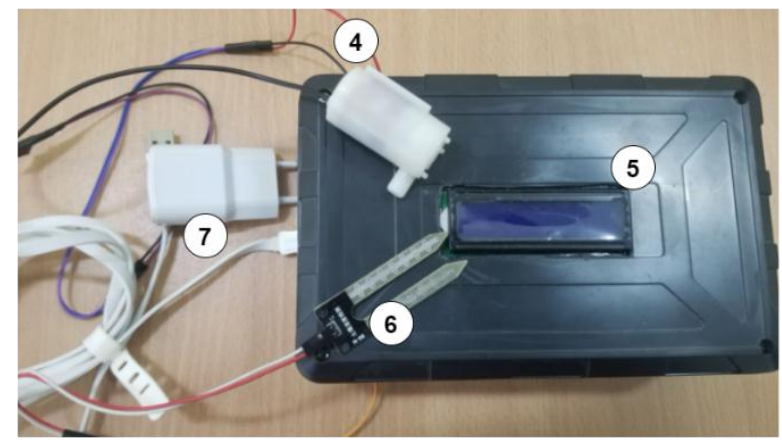

Gambar 9. Bagian Luar Model

Berbeda dengan bagian dalam model, di bagian luar ini terdapat komponen-komponen yang digunakan untuk menerima dan menampilkan data. Komponen yang ditempatkan di luar adalah sebagai berikut: 4) pompa air, 5) LCD yang sudah terpatri dengan komponen antarmuka I2C di baliknya 6) bagian utama sensor kelembaban, dan 7) daya utama model sebesar 5V DC. Model ini kemudian dievaluasi melalui eksperimen selama 24 jam dan menghasilkan data timeseries untuk dianalisis selanjutnya.

Hasil yang didapatkan berupa data-data yang telah diunggah ke peladen milik Blynk. Data-data tersebut diunduh dan kemudian dianalisis untuk melihat tingkat kelembaban dari segi Moisture Value, Relative Humidity, dan aktivasi pompa berdasarkan kondisi yang telah diprogramkan ke model.

Data hasil dari pemantauan selama 24 jam berisikan 1440 baris data. Sample data mentah pemantauan yang didapatkan dari peladen ditunjukkan pada Tabel 4.

Tabel 4. Sampel Data Mentah

\begin{tabular}{ccc}
\hline Time & $\begin{array}{c}\text { Moisture } \\
\text { Value }\end{array}$ & Relative Humidity \\
\hline 01:30:00 & 927,58 & 18,65486 \\
01:31:00 & 831,0588235 & 37,52511765 \\
$01: 32: 00$ & 642,84 & 74,32256 \\
$01: 33: 00$ & 627,254902 & 77,36947059 \\
$01: 34: 00$ & 620,94 & 78,60404 \\
$01: 35: 00$ & 610,94 & 80,55906 \\
$01: 36: 00$ & 606,5490196 & 81,41743137 \\
$01: 37: 00$ & 602,76 & 82,15814 \\
$01: 38: 00$ & 599,3921569 & 82,79954 \\
$01: 39: 00$ & 594,9 & 83,69462745 \\
\hline
\end{tabular}

Data Moisture Value kemudian dikonversikan dalam bentuk persentase dengan menggunakan rumus Analog Output dan Moisture Percentage. Sample hasil dari konversi nilai MV ke persentase MV ditunjukkan pada Tabel 5.

Tabel 5. Sampel Hasil Akhir Data

\begin{tabular}{lcc}
\hline Time & Moisture (\%) & $\begin{array}{c}\text { Relative } \\
\text { Humidity }\end{array}$ \\
\hline 01:30:00 & 9,33 & 18,65 \\
01:31:00 & 18,76 & 37,53 \\
01:32:00 & 37,16 & 74,32 \\
01:33:00 & 38,68 & 77,37 \\
01:34:00 & 39,30 & 78,60 \\
01:35:00 & 40,28 & 80,56 \\
01:36:00 & 40,71 & 81,42 \\
01:37:00 & 41,08 & 82,16 \\
01:38:00 & 41,41 & 82,80 \\
01:39:00 & 41,85 & 83,69 \\
\hline
\end{tabular}

Dari data akhir menampilkan perubahan kelembaban tanah baik dalam bentuk cair maupun gas. Kelembaban dari kedua sisi tersebut mengalami kenaikan yang cukup signifikan dari 9\% ke 41\% (nilai persentase Moisture), dan dari 18,65\% ke 83,69\% (nilai Relative Humidity).

Hasil statistik deskripsi dari data pemantauan yang didapatkan oleh model ditunjukkan pada Tabel 6.

Tabel 6. Data Statistik Pemantauan Model

\begin{tabular}{lrr}
\hline & Moisture (\%) & \multicolumn{1}{c}{$\begin{array}{c}\text { Relative } \\
\text { Humidity }\end{array}$} \\
\hline Mean & 40,60510828 & 81,21014175 \\
Minimum & 9,327468231 & 18,65486 \\
Maximum & 44,33431085 & 88,66876 \\
Count & 1440 & 1440 \\
\hline
\end{tabular}


Dari pemantauan yang dilakukan oleh model selama 24 jam, nilai rata-rata kelembaban (Moisture dan Relative Humidity) mencapai $40,60 \%$ dan $81,21 \%$. Nilai minimum yang dicapai keduanya mencapai 9,32\% dan $18,65 \%$. Sedangkan nilai maksimum dari keduanya mencapai $44,33 \%$ dan 88,66 . Nilai terendah yang terbaca oleh model didapatkan saat tanah masih dalam kondisi kering, sehingga nilai kelembabannya kurang. Sebaliknya, nilai maksimum didapatkan ketika tanah dibasahi dengan pompa kekuatan penuh.

Untuk melihat jelas data pemantauan yang terjadi selama eksperimen dilakukan maka data disajikan dalam bentuk grafik. Grafik perubahan data Moisture (\%) dari waktu ke waktu ditunjukkan pada Gambar 10.

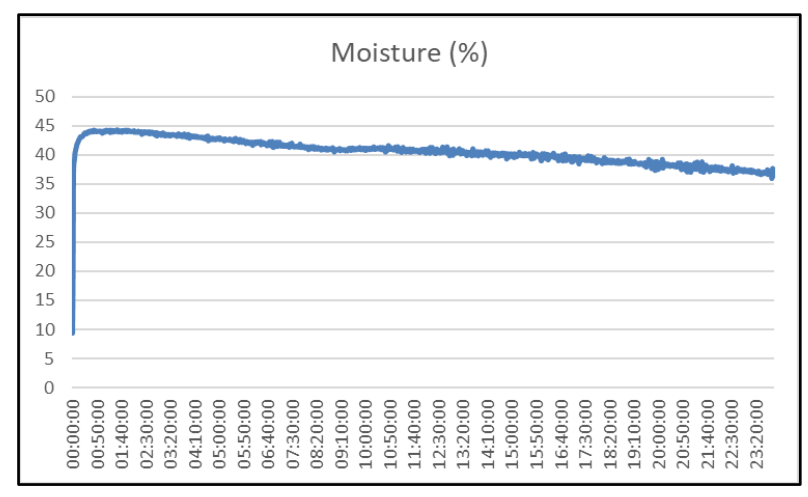

Gambar 10. Grafik Data Moisture (\%)

Hasil dari pemantuan yang dilakukan selama 24 jam penuh, terjadi kenaikan nilai Moisture (\%) yang signifikan. Hal ini terjadi karena tanah yang kering terdeteksi oleh sensor, dan model menyalakan pompa untuk mengairi tanah tersebut. Berdasarkan data ini, Moisture (\%) di dalam tanah mencapai nilai tertinggi hingga 44.33\%. Grafik Data Relative Humidity ditunjukkan pada Gambar 11.

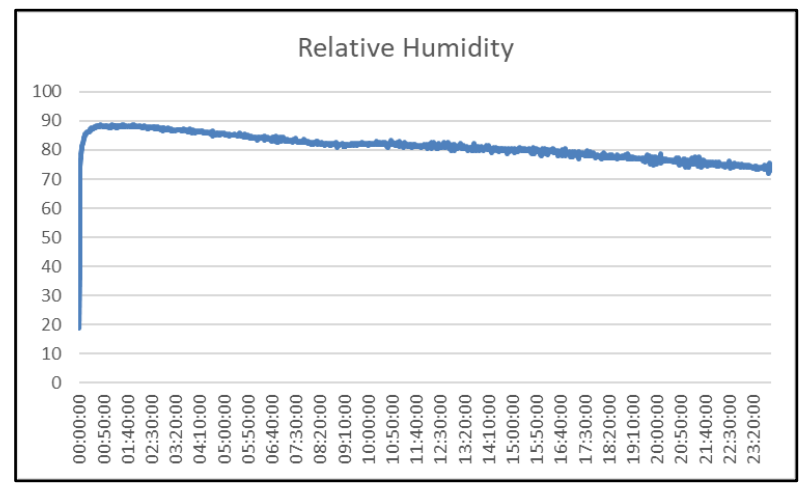

Gambar 11. Grafik Data Relative Humidity

Grafik ini memiliki kemiripan dengan grafik sebelumnya. Namun grafik ini menggambarkan perubahan nilai RH dari waktu ke waktu. Meskipun tidak dijadikan sebagai indikator untuk menyalakan pompa. Nilai $\mathrm{RH}$ mengalami perubahan yang diakibatkan oleh pengaktifan pompa yang dilakukan oleh model. Nilai RH tertinggi yang ditangkap oleh sensor mencapai $88.66 \%$. Lebih tinggi daripada kandungan Moisture (\%)

Kedua grafik ini (Moisture dan Relative Humidity) mengalami kondisi structural break yang di mana terjadi perubahan kondisi secara tiba-tiba secara tajam. Perubahan mendadak ini terjadi pada menit ketiga yang dimana kenaikan kelembaban naik hingga dua kali lipat. Terjadinya structural break ini adalah tanda bahwa pengaktifan pompa dan proses pengairan berhasil.

Dikarenakan terdapat kemiripan grafik di antara nilai Moisture (\%) dengan Relative Humidity, maka analisa korelasi Pearson dilakukan untuk mencari korelasi di antara nilai persentase Moisture, Relative Humidity (RH), dan waktu (Time). Hasil dari korelasi di antara data-data ini ditunjukkan pada Tabel 7.

Tabel 7. Hasil Korelasi Data Pantauan

\begin{tabular}{cccc}
\hline No & Fitur 1 & Fitur 2 & Korelasi \\
\hline 1 & Moisture & RH & 1 \\
2 & RH & Time & -0.842 \\
3 & Moisture & Time & -0.842 \\
\hline
\end{tabular}

Korelasi di antara nilai Moisture (\%) dan Relative Humidity memiliki nilai sempurna, sehingga bisa dikatakan bahwa tidak ada anomali ataupun kecacatan deteksi yang dibaca oleh sensor. Jika terjadi perbedaan di antara kedua variabel ini, bisa dikatakan bahwa terjadi anomali atau kejanggalan baik dari sensor, maupun proses pengambilannya. Sedangkan data lainnya, apabila dikorelasikan dengan waktu (Time) maka muncul nilai dibawah 0 yang bisa diartikan sebagai tidak adanya korelasi di antara data tersebut.

Dari hasil ini bisa dinyatakan bahwa fitur utama dari data pemantauan ini adalah Moisture (\%) dan Relative Humidity. Ilustrasi korelasi dua fitur utama teragregasi tersebut ditunjukkan pada Gambar 12.

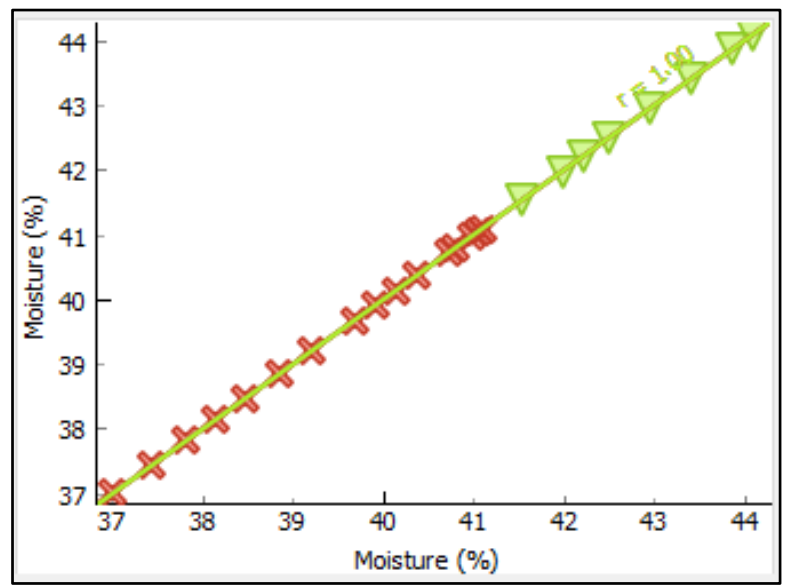

Gambar 12. Grafik Korelasi Nilai Teragregrasi 
Korelasi yang ditampilkan ini merupakan nilai korelasi Pearson dari Moisture (\%), dan Relative Humidity teragregasi. Kesempuranaan korelasi ini ditunjukkan dengan hasil korelasi di antara keduanya $(r=1)$. Simbol-simbol yang ada di grafik ini mewakili tingkat kelembaban yang terpantau oleh model. Dari hasil data yang didapatkan bisa diperhitungkan berapa kali pompa aktif tinggi, aktif rendah, maupun mati: Diagram pengaktifan pompa ditunjukkan pada Gambar 13.

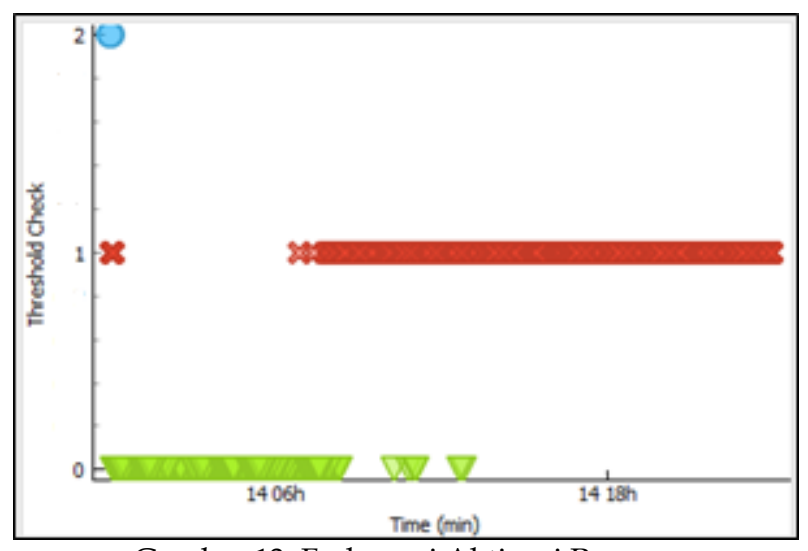

Gambar 13. Frekuensi Aktivasi Pompa

Berdasarkan grafik di atas, bisa dipastikan bahwa pompa dinyalakan dalam keadaan tenaga penuh sebanyak dua kali. Karena tanah sudah dalam keadaan benar-benar basah, maka pompa dihentikan seketika. Beberapa jam kemudian pompa kembali dinyalakan dalam posisi tenaga rendah untuk menjaga kestabilan tingkat kelembaban tanah. Hal ini dilakukan terus menerus hingga penyimpanan air habis atau adanya interupsi dari model maupun dari listrik. Pompa diaktifkan dengan tenaga penuh sebanyak dua kali, dengan tenaga rendah sebanyak 962 kali, dan dimatikan sebanyak 476 kali.

Persentase kondisi kelembaban tanah disajikan sebagai diagram persentase ditunjukkan pada Gambar 14.

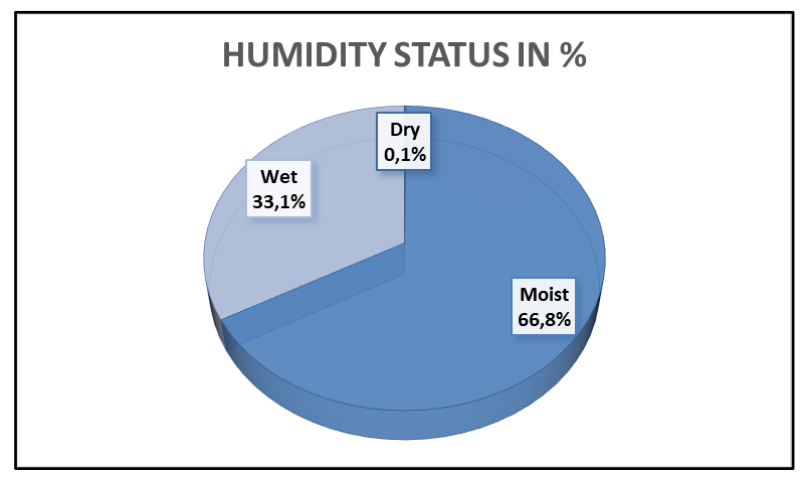

Gambar 14. Persentase Kelembaban Tanah

Diagram persentase di atas merefleksikan tingkat kelembaban tanah selama model diaktifkan. Dalam kurun waktu 24 jam, model ini mendeteksi tanah kering sebanyak $0.1 \%$, tanah lembab sebanyak $66.8 \%$, dan tanah basah sebanyak 33.1\%. Tingginya erekuensi tanah yang lembab disebabkan oleh aktifnya pompa tenaga rendah yang membasahi tanah setiap waktu. Berdasarkan hasil-hasil dari eksperimen yang dilakukan, baik data Moisture Value, Relative Humidity, dan Frekuensi pengaktivan pompa, bisa dipastikan bahwa model dengan sukses mengambil, memproses dan mengunggah data kelembaban dengan baik. Hal ini dibuktikan dengan stabilnya kelembaban tanah hingga 66.78\% sepanjang waktu model dalam posisi menyala

\section{KESIMPULAN}

Perkembangan teknologi di jaman modern terus berlanjut dan berdampak pada kehidupan manusia. Teknologi juga membantu dalam bidang pertanian untuk meningkatkan produksi pangan hingga tingkat negara. Namun terdapat masalah utama yang menjadi beban para petani, sehingga menghambat produksi pangan. Oleh karena itu, penelitian ini mengusulkan sebuah model berbasiskan Internet of Things untuk mengurangi beban para petani dalam hal pengairan sawah. Model yang diusulkan oleh penelitian ini memiliki kemampuan untuk memantau serta mengendalikan pengairan secara otomatis sesuai dengan kondisi kelembaban tanah. Model akan membaca tingkat kelembaban tanah, dan melakukan pengairan sesuai dengan tingkat kelembabannya. Berdasarkan hasil evaluasi, terjadi structure break di grafik data kelembaban. Dengan adanya structure break ini membuktikan bahwa terjadi peningkatan kelembaban di dalam tanah. Selain itu data-data yang diambil memiliki korelasi yang sangat tinggi $(\mathrm{r}=1)$, meskipun memiliki nilai yang berbeda. Sehingga dapat dipastikan, sensor bekerja dengan baik memantau keadaan sawah. Jika diliat dari segi frekuensi pengaktifan pompa, model menyalakan pompa sebanyak dua kali ketika tanah kering, 961 kali selama tanah lembab, dan dimatikan sebanyak 476 kali selama tanah basah. Hal ini membuktikan bahwa model sukses mengatur irigasi untuk mengontrol kelembaban tanah.

Namun dari penelitian yang dilakukan masih terdapat kekurangan yang harus diperhatikan. Penelitian hanya menganalisis data kelembaban, sehingga data-data lain seperti suhu disertakan. Selain itu data yang didapatkan hanya data musim kemaran, sehingga data kelembaban di musim hujan belum ada. Banyak peningkatan yang bisa dilakukan berupa, penambahan analisis AI maupun machine learning, pemantauan lebih detail dengan banyak sensor, dan implementasi banyak model untuk pemantauan dan pengendalian di daerah yang lebih luas. Selain itu, forecasting cuaca lokal untuk meningkatkan hasil panen juga dapat dilakukan. 


\section{UCAPAN TERIMA KASIH}

Ucapan terima kasih kepada Lembaga Penelitian dan Pengabdian Kepada Masyarakat (LPPM) Universitas Semarang atas dana penelitian serta kesempatannya.

\section{DAFTAR PUSTAKA}

[1] H. Lubis, R. F. Rahmat, J. Karansa, and S. Purnamawati, "Monitoring System of Rice Plant Growth Using Microcontroller Sensor," in Journal of Physics: Conference Series, Jul. 2019, vol. 1235, no. 1, p. 12116, doi: 10.1088/17426596/1235/1/012116.

[2] M. Hossain, S. Sikder, A. Husna, and S. Sultana, S. Akhter, A. Alim, and JC. Joardar, "Influence of Water Stress on Morphology, Physiology and Yield Contributing Characteristics of Rice," SAARC J. Agric., vol. 18, no. 1, pp. 61-71, Jul. 2020, doi: 10.3329/sja.v18i1.48382.

[3] J. Zhang, Y. Li, H. Zahng, P. Dong, and C. Wei, "Effects of different water conditions on rice growth at the seedling stage," Rev. Caatinga, vol. 32, no. 2, pp. 440-448, May 2019, doi: 10.1590/1983-21252019v32n217rc.

[4] I. Saraswati, V. D. Puspitasari, S. P. Anggoro, Alimuddin, T. Firmansyah, R. O Khastini, and U Mardono, "Applications of temperature and humidity monitoring system at aerophonic plants based on IoT," MATEC Web Conf., vol. 218, p. 03017, Oct. 2018, doi: 10.1051/matecconf/201821803017.

[5] S Nath, J. K. Nath, and K. C. Sarma, "Iot Based System for Continuous Measurement and Monitoring of Temperature, Soil Moisture and Relative Humidity," in IAEME Publication, 2018, pp. 106-113.

[6] C. G. Priya, M. Abishek Pandu, and B. Chandra, "Automatic plant monitoring and controlling system over GSM using sensors," in Proceedings - 2017 IEEE Technological Innovations in ICT for Agriculture and Rural Development, TIAR 2017, Jan. 2018, vol. 2018-Janua, pp. 173-176, doi: 10.1109/TIAR.2017.8273710.

[7] M. Danita, B. Mathew, N. Shereen, N. Sharon, and J. J. Paul, "IoT Based Automated
Greenhouse Monitoring System," in Proceedings of the 2nd International Conference on Intelligent Computing and Control Systems, ICICCS 2018, Mar. 2019, pp. 1933-1937, doi: 10.1109/ICCONS.2018.8662911.

[8] D. Mishra, A. Khan, R. Tiwari, and S. Upadhay, "Automated Irrigation System-IoT Based Approach," Nov. 2018, doi: 10.1109/IoTSIU.2018.8519886.

[9] B. Bohara, S. Maharjan, and B. R. Shrestha, "IoT Based Smart Home using Blynk Framework," arXiv, Jul. 2020.

[10] EINSTRONIC, "Nodemcu," Einstronic, 2017.

[11] A. C. Bento, "IoT: NodeMCU 12e X Arduino Uno, Results of an experimental and comparative survey," Int. J. Adv. Res. Comput. Sci. Manag. Stud., vol. 6, no. 1, pp. 46-56, 2018.

[12] A. A. Dahoud and M. Fezari, "NodeMCU V3 For Fast IoT Application Development," Notes. pp. 1-13, 2018, [Online]. Available: https://galopago.github.io/assets/pdf/Node MCUV3.pdf.

[13] Directorate of Research on Women in Agriculture, "Cultivation Practices- Water Management."

https://agritech.tnau.ac.in/expert_system/pad dy/cultivationpractices3.html (accessed Jun. 08, 2020).

[14] M. Syakir, I. Mohd, and S. Mashori, "IoT-Based Socket Control System," vol. 1, no. 1, pp. 296302, 2020, doi: 10.30880/peat.2020.01.01.03 2.

[15] C. Zhang and N. Lu, "Measuring Soil-Water Density by Helium Pycnometer," J. Geotech. Geoenvironmental Eng., vol. 144, no. 9, 2018, doi: 10.1061/(ASCE)GT.1943-5606.0001929.

[16] A. Rahimabadi and A. A. Jamali, "Detecting and Calculating the Soil Moisture Using Microwave Imagery (Case Study: Miyankale, Mazandaran)," J. Radar Opt. Remote Sens., vol. 1, no. 1, pp. 46-57, Mar. 2019.

[17] A. Geetha, A. Dhamodharan, G. Barani, L. Jegadheesan, and P. Gowthamkrishnan, "Design and Implementation of Soil Moisture Detector using Arduino," Int. Res. J. Eng. Technol., vol. 7, no. 5, pp. 4559-4563, 2020. 